\title{
The relationship between hand hygiene and health care-associated infection: it's complicated
}

\author{
This article was published in the following Dove Press journal: \\ Infection and Drug Resistance \\ 29 January 2015 \\ Number of times this article has been viewed
}

\section{Mary-Louise McLaws}

Healthcare Infection and Infectious Diseases Control, School of Public Health and Community Medicine, UNSW Medicine, UNSW Australia, Sydney, NSW, Australia
Correspondence: Mary-Louise McLaws Healthcare Infection and Infectious Diseases Control, Level 3, School of Public Health and Community Medicine, UNSW Medicine, UNSW Australia, Sydney, NSW 2052, Australia

Tel +6I 293852586

Emailm.mclaws@unsw.edu.au

\begin{abstract}
The reasoning that improved hand hygiene compliance contributes to the prevention of health care-associated infections is widely accepted. It is also accepted that high hand hygiene alone cannot impact formidable risk factors, such as older age, immunosuppression, admission to the intensive care unit, longer length of stay, and indwelling devices. When hand hygiene interventions are concurrently undertaken with other routine or special preventive strategies, there is a potential for these concurrent strategies to confound the effect of the hand hygiene program. The result may be an overestimation of the hand hygiene intervention unless the design of the intervention or analysis controls the effect of the potential confounders. Other epidemiologic principles that may also impact the result of a hand hygiene program include failure to consider measurement error of the content of the hand hygiene program and the measurement error of compliance. Some epidemiological errors in hand hygiene programs aimed at reducing health care-associated infections are inherent and not easily controlled. Nevertheless, the inadvertent omission by authors to report these common epidemiological errors, including concurrent infection prevention strategies, suggests to readers that the effect of hand hygiene is greater than the sum of all infection prevention strategies. Worse still, this omission does not assist evidence-based practice.
\end{abstract}

Keywords: compliance, epidemiological principles, study design, bacteria, control, multiple drug resistance

\section{Background History of the leading guidelines}

The mid-19th century work of Labaraque, ${ }^{1}$ a pharmacist, and Semmelweis, ${ }^{2}$ an obstetrician, provided powerful historical support for the hypothesis that clinicians' hands carried pathogenic organisms that could be transmitted to susceptible patients who subsequently developed infection. By the late 20th century, evidence was mounting about the risk to patients from transient pathogens on health care workers' (HCWs') hands. ${ }^{3-6} \mathrm{~A}$ handwashing guideline was developed by the Centers for Diseases Control (CDC) in $1975^{7}$ and updated in $1985 .{ }^{8}$ The CDC recommended nonmedicated soap and water for routine hand-washing and medicated soap and water hand-washing prior to invasive procedures. ${ }^{8}$ Alcohol-based hand rub (ABHR) was indicated when soap and water washing was unavailable. ${ }^{8}$ The Association for Practitioners in Infection Control produced a hand hygiene guideline in 1988, updated in 1995, which, for the first time, explicitly recommended HCWs use ABHR on leaving a patient's room. ${ }^{9}$ In 2002, CDC hand hygiene guidelines provided evidence for the transmission of pathogens on hands, models of transmission, the association between hand hygiene and reduced risk 
of transmission of health care-associated infections (HAIs), and the actions and efficiency of hand hygiene agents. ${ }^{10}$ This guideline was developed in collaboration with the Healthcare Infection Practices Advisory Committee (IPAC), the Society for Hospital Epidemiologists, and the Infectious Diseases Society of America. In 2009, the World Health Organization (WHO) launched the "Clean Hands Save Lives" campaign with the release of a guideline. ${ }^{11}$ The guideline was developed with the aim that the content was to be appropriate for a wide range of resourced health care settings. Hand hygiene with ABHR was now specifically recommended for routine use within a new paradigm of indications, "My five moments for hand hygiene". ${ }^{12}$ These five indications were chosen to maximize the interruption of the transmission route of pathogens: two before patient contact, two after patient contact, and one after contact with the patient's zone. An additional goal of the guidelines was to standardize hand hygiene training and provide the first standardized tool for the collection of hand hygiene compliance data to reduce inter-rater bias during the human auditing process.

As countries made pledges to the Clean Hands Save Lives campaign post its 2009 launch, a flourish of national or statewide hand hygiene awareness and improvement interventions ensued, including those in Australia, ${ }^{13}$ the United Kingdom, ${ }^{14}$ Italy, ${ }^{15}$ Mali, ${ }^{15}$ Pakistan, ${ }^{15}$ Saudi Arabia, ${ }^{15}$ and the United States. ${ }^{16}$ During this period, other infection prevention strategies were implemented in highly resourced health care settings nationally or statewide. ${ }^{17-24}$ These strategies include the reformist approach of packaging many infection prevention strategies of varying levels of evidence for prevention, which is referred to as a "bundle", and all elements of the bundle that must be complied with. Bundles have been developed for ventilator-associated pneumonia, ${ }^{25}$ catheter-associated urinary tract infection, ${ }^{26}$ and central-line-associated bloodstream infection (CLABSI), ${ }^{27}$ which are widely adopted outside the US. ${ }^{21-24,28-34}$ These bundles include hand hygiene. Effective singular infection prevention approaches that have been adopted include aseptic insertion of peripheral venous catheters, ${ }^{27}$ chlorhexidine baths to reduce the incidence of CLABSI in intensive care units (ICUs), ${ }^{35,36}$ hospital-wide antibiotic stewardship, ${ }^{37}$ hospitalwide environmental cleaning, ${ }^{38,39}$ isolation, ${ }^{40}$ screening, and decolonization regimes, ${ }^{14,41,42}$ and surveillance. ${ }^{43,44}$ Therefore, it would be unusual for a hand hygiene intervention in high-resourced health care settings ${ }^{45}$ to have been initiated in the absence of multiple concurrent infection strategies that would include bundles or several singular infection prevention strategies. ${ }^{13,14,46,47}$
Prior to the WHO guideline ${ }^{11}$ release, two tertiary hospitals in the US evaluated the impact of an active methicillinresistant Staphylococcus aureus (MRSA) screening of all ICU admissions. The hospitals also experienced multiple concurrent infection prevention strategies including the 5 Million Lives Campaign, surgical infection reduction initiatives, Keystone ventilator and central line bundles, and a CDC-led hand hygiene campaign. ${ }^{44}$ The screening program commenced when hand hygiene compliance rate reached $>70 \%$, and after 6 months the ventilator-associated pneumonia rate reduced from 0.954 days to 0.171 per 1,000 patient-days and the bloodstream infection (BSI) rate from 0.219 to 0.128 per 1,000 patient-days. ${ }^{44}$ The reduction in infection may have been the effect of screening or due to other singular or multiple strategies including high hand hygiene. Alternatively, the effect may have been an additive effect between hand hygiene and the other concurrent infection control strategies.

In response to the WHO guideline that was released in 2007 and since the final version was released in 2009, a plethora of hygiene campaigns have been published. ${ }^{47,48}$ Yet, rarely have individual publications that report on national or local success in reducing HAIs considered the confounding impact of concurrent infection prevention activities in their health care settings on HAI rates. Powerful drivers for the implementation of multiple infection prevention strategies that could distort the effect of hand hygiene include expectations, ${ }^{43}$ the need to reduce the cost associated with HAIs, ${ }^{49}$ and pressure of public reporting of key performance indicators that may not have been fully validated or adjusted to allow sound comparisons to be made with prior rates. ${ }^{50,51}$

An overview of important epidemiology principles that can adversely impact the results is given below and will use hand hygiene compliance and HAI as examples. A selection of papers published after the WHO guideline was released in 2009, mostly national interventions or multicenter, will be used to illustrate how errors in the application of these principles may impact hand hygiene campaigns that attempt to directly link hand hygiene improvements with reduction in HAIs. These papers are used to discuss the inability to disentangle a posteriori the effect of one or more bundled or singular infection prevention strategies from the effect of a hand hygiene program on HAI rates.

\section{Epidemiological principles and pitfalls of hand hygiene research Errors inherent in study designs}

Cost-effective study designs to test the impact of the provision of ABHR at point of care, hand hygiene education, 
antibiotic stewardship, and environmental cleaning on HAIs include the experimental design of randomized control trial (RCT) and quasi-experimental designs such as Before-Intervention-After (B-A), time series, and cohort. ${ }^{52}$ It is ethically difficult to justify the RCT design unless the passive arm of the trial includes an alternative intervention. Similarly, cohort design requires two intervention groups with a follow-up period for infection and extrinsic risk data collection. A period for follow-up is typically restricted to less than 24 months because of resource costs. The pitfall in a cohort or RCT design with a short follow-up period in a high resourced ward or hospital is that the number of HAIs will be small after stratifying by each level of intervention. This makes it difficult to identify a statistical difference for HAI rates associated with the hand hygiene intervention groups. The use of B-A design has the advantage of having a high probability of sufficient numbers of HAIs in the entire before- and the entire after-period to establish a statistical difference. There may be the potential for intrinsic risk factors for infection to be different in the patient populations during the two periods. However, the likelihood that the level of intrinsic risk factors for HAIs being significantly worse during the before period is extremely low. With the small number of HAIs that remain after stratifying by two different arms of a prospective concurrent intervention, the B-A and time series designs are the logical choices. However, there are other important epidemiologic pitfalls that are inherent in all study designs, including measurement error, short follow-up periods, and the confounding of the effect of a study factor due to concurrent infection strategies.

\section{The epidemiologic principle of measurement error}

Measurement error is an important epidemiologic principle ${ }^{52}$ concerned with the unintended variation in the measurement of the exposure factor, sometimes referred to as the "study factor" or "predictive variable". Measurement error can also occur in the measurement of the outcome factor. If a hand hygiene intervention uses online education components and in-service training sessions to improve hand hygiene compliance, then the education material and method is the exposure/study factor and compliance is the outcome factor. Alternatively, if improved hand hygiene is examined as a causal factor for the reduction in HAIs, then hand hygiene is tested as the predictor (study factor) of HAIs (outcome factor). Unacknowledged measurement error in either the study factor or outcome factor may cause the hypothesis that the study factor (intervention) caused the outcome factor (increase in hand hygiene or decrease in HAI) to be incorrectly accepted.

To answer whether there was measurement error in the study factor, ask of the paper "Was exposure to the study factor (eg, intervention) defined?" Exposure to the study factor should be defined and used to determine whether the participants received the study factor in full or in part, such as attendance to all online learning components and in-service training sessions. "Have participants been correctly categorized as being exposed or not exposed to the study factor?" and "Did every participant receive the intervention in a consistent manner during the intervention period?" will provide information about whether the researchers measured exposure or simply assumed exposure. In the absence of evidence that participants were exposed in accordance with the definition, one must assume that measurement error of participants' exposure to the study factor has possibly occurred. We must then decide how seriously this measurement error will impact the validity of the outcome.

To answer whether there was measurement error of the outcome factor, ask the paper "Was outcome defined?" This question will answer whether the definition of compliance was simply the observation of a sample of HCWs using ABHR in accordance with the Five Moments or whether they were also required to use the correct technique while performing hand hygiene. "Was the definition applied consistently to all HCWs observed by the rater (eg, auditor)?" will answer the level of intra-rater reliability of the measurement by the one auditor. "Was the outcome factor measured consistently over time by all the different raters (eg, auditors)?" will answer the level of inter-rater reliability of the measurement between multiple auditors to consistently apply the definition of hand hygiene and therefore correctly categorize HCWs into compliers and noncompliers.

\section{Implications of measurement error}

A hand hygiene intervention may not always result in a reduction in HAIs due to failure of full saturation of the exposure factor, eg, the intervention message. The Australian National Hand Hygiene Initiative commenced in 2009 and required $\mathrm{HCWs}$ at 521 hospitals to have undertaken and understood the online education about My Five Moments and attended in-service training (study factors). ${ }^{13}$ However, the extent of exposure of HCWs to information on My Five Moments ${ }^{12}$ or their level of understanding of these indications has not been publically reported. After 2 years, hand hygiene compliance increased from $43.6 \%$ $(6,431 / 14,740$ moments $)$ to $67.8 \%(106,851 / 157,708)$ 
$(P<0.001) .{ }^{13}$ However, this improvement did not affect the outcome factors (hospital-onset [HO] bacteremia) over this period for hospital-onset $S$. aureus bacteremia (HO-SAB) $(P=0.59)$, HO-methicillin resistant $S$. aureus (HO-MRSA) bacteremia $(P=0.58)$, and $\mathrm{HO}$ methicillin-sensitive $S$. aureus (HO-MSSA) bacteremia $(P=0.30)$. Only after combining the rates of HO-MRSA with non-hospital-onset MRSA bacteremia was a statistical difference identified $(P=0.008)$. These results suggest that measurement error has occurred in the study factor (hand hygiene) or in the outcome factors (HO-SAB, HO-MRSA, HO-MSSA), or the validity of the outcome factor (combining HO- with non-HO MRSA), or that the study factor was not associated with the outcomes. Error associated with measuring HO-MRSA is small, as the microbiological test before and during the study period is likely to be applied in a standardized method. Therefore, the most likely explanation is that error in measuring the study factor (hand hygiene) produced an overinflated rate of improvement or that the study factor was not associated with this particular outcome factor.

Direct observation and electronic monitoring of dispensers of hand hygiene solution produce different number of opportunities for hand hygiene and compliance rates. ${ }^{53,54}$ The direct observation method may produce an unquantifiable proportion of compliance, which is due to the Hawthorne effect. ${ }^{53}$ Hand hygiene may not always produce the positive impact we expect if the Hawthorne effect causes high compliance rates that are not sustained after the audit period. Hand hygiene compliance (study factor) was not predictive of a resolution of an outbreak (outcome factor) even when the median hand hygiene compliance rate prior to the outbreak was $100 \%$ and compliance in response to the outbreak was equally high, $98 \%(P=0.93) .{ }^{55}$ The outbreak in the presence of very high hand hygiene compliance is counterintuitive unless the compliance rate (study factor) prior to the outbreak was falsely high due to measurement error, specifically the Hawthorne effect. Alternatively, improved surveillance of multiple drug resistant organisms (MDROs) during and after an outbreak may identify more MDROs during the outbreak, making hand hygiene compliance appear ineffective. Publication bias toward positive results prevents readers from knowing that surveillance bias occurs frequently.

\section{Other measurement errors}

Short duration of follow-up of a newly acquired behavior may falsely classify the actor as highly compliant when there has been insufficient time for the new behavior to be validated. In the case of hand hygiene, if the follow-up period is too short and the new level of compliance may be difficult to sustain without a maintenance stage, ${ }^{56}$ then measurement error will occur. According to the "transtheorectical model", 56 there are five processes of change or stages before a new behavior can become embedded. Helder et $\mathrm{al}^{57}$ understood that human behavior often returns to a comfortable pre-intervention level when they introduced a sequential hand hygiene campaign over a decade. A reduction in BSI (outcome) was achieved between 2000 and $2011,{ }^{57}$ and the follow-up period of a decade was extensive to allow for improved hand hygiene behavior to become embedded. However, when direct observation is used, there will always remain the possibility of overestimation of hand hygiene compliance due to the Hawthorne effect (measurement error).

The WHO guidelines ${ }^{11}$ provide a hand hygiene compliance audit tool for ABHR or soap and water use and instructions for the technique of hand hygiene. ${ }^{11}$ The audit tool does not include a measurement of the hand hygiene technique. ${ }^{11}$ The correct hand hygiene technique requires the actor to perform seven poses while using ABHR: rubbing palms together in a circulation motion, fingertips moving in circular motion on the palm of the opposite hand, palm to palm with fingers from opposing hands interlocking, four fingers grip interlocking four fingers on the opposing hand, palm of hand onto the back of the opposing hand with fingers between fingers, rubbing thumbs, rubbing wrists. Ineffective hand hygiene technique may result in a hand hygiene intervention failing to affect the rate of MDROs. ${ }^{58}$ The effectiveness of hand hygiene with ABHR to remove MRSA from fingertips relies on the technique of several of the above poses during approximately 20 seconds of rubbing. After contact with patient's environment, $10 \%$ of HCWs tested positive for MRSA on their fingertips of whom $41 \%$ had used ABHR or chlorhexidine soap wash. ${ }^{59}$ When the aim of an intervention is to reduce HAIs (outcome factor) through hand hygiene (study factor), then the definition of hand hygiene may need to consider the inclusion of the technique.

Insufficient volume of ABHR can also impact the effectiveness of hand hygiene (study factor) on the recovery of pathogenic microorganisms on HCWs' hands (outcome factor). The European Norm (EN) 1500 is a standard used to approve ABHR for use in the health care setting. The volume of ABHR affects the EN 1500 pass criterion requiring a $\log 10$ reduction of microorganisms from hands. At least 2.5-3 mL of ABHR is required to achieve microorganism reduction in accordance with EN 1500. ${ }^{60}$ Log reduction increases with the volume of product, but it plateaus when too much product is used. When ABHR (study factor) is linked to log reduction of microorganisms (outcome factor) from HCWs' hands, then the method 
of recovery of the microorganism and the choice of MDRO must not adversely impact the measurement of the outcome factor. The glove juice method of immersing the whole hand to recover MDROs ${ }^{61}$ is superior to swabbing hands or fingertip plate method, but it is not always used. When MDRO isolation is restricted to just MRSA (outcome factor), low yields similar to the normal fingertip plate method are produced. ${ }^{59,60}$ Poor association between infection rates (outcomes) and hand hygiene (study factor) may be the result of these errors.

Infection control strategies can impact the outcome or act as a proxy for the outcome (ie, directly or indirectly increase or decrease the outcome), and when these strategies are not the study factor of interest these strategies become potential confounders. Potential confounders have the ability to under- or overestimate the effect of the current study factor of interest. ${ }^{62}$ Environmental cleaning, cohorting patients, and hand hygiene are classic responses to an MDRO outbreak. In fact, it would be unethical not to implement a bundle of interventions where patients' welfare and, indeed, lives are at stake. Unfortunately, this confounds the ability to elucidate which element of the bundle worked and which did not. Collection and discussion of confounders in multicenter sites is rare in hand hygiene interventions. ${ }^{63-66}$ Confounding may have occurred during routine ICU surveillance between 1997 and 2010 in European hospitals. ${ }^{67}$ Infections remained stable or trended down, but device utilization also declined ${ }^{67}$ The effect of surveillance on the downward trend in infection can be determined if the effect of the potential confounder (reduction in devices utilization) is controlled for in the study design or adjusted during analysis.

During a hand hygiene campaign, change to common risk factors for HAIs extrinsic to the campaign that may contribute to the improvement in MDRO rates are referred to as "potential confounders" until the effect of these factors are controlled by design or adjusted by analysis. New or reinvigorated infection prevention activities in the intervention ward or elsewhere in the hospital are potential confounders and include the following:

- improved surveillance definition,

- improved recovery methods for MDROs,

- improved appropriate local antibiotic prescribing practices,

- improved management of prophylaxis administration that includes correct time for initiation and correct duration,

- improved bed management,

- improved nurse-to-patient ratio,

- change in bed occupancy,

- change in diagnostic related groups (DRGs),
- screening for MDRO on admission with preemptive isolation,

- isolating or cohorting MDRO,

- adherence to new infection prevention bundle,

- timely removal of peripheral intravascular devices and removal of central venous catheters (CVCs) on discharge from ICUs, and

- new environmental cleaning regime or adherence to the cleaning schedule.

Evidence for the success of a hand hygiene program requires consideration of measurement error of hand hygiene and infection rates and measurement errors of other factors and potential confounders that are extrinsic to the hand hygiene program, as listed above. Post hoc failure to consider concurrent infection prevention strategies other than the hand hygiene intervention is discussed in the next section.

\section{The inability to disentangle a posteriori effects of multiple infection prevention strategies}

The launch in 2004 in the United Kingdom of a national MRSA screening program (study factor) was refreshed in 2006 and reviewed for success in 2008 and was identified as a national success. ${ }^{68-70}$ Patients who were initially screened on admission were considered to have a higher risk of MRSA, and included certain emergency admissions and elective surgical procedures, renal patients, previously MRSA-positive patients, cancer patients, and patients admitted from residential aged care. The program resulted in significant declines in rates for MRSA (1.88-0.91/10,000 bed-days) and Clostridium difficile infection (CDI) (16.75-9.49/10,000 bed-days), but not MSSA bacteremia (outcome factors). ${ }^{14} \mathrm{~A}$ reduction in infections for at least two quarters was attributed to visits by the Department of Health improvement teams to Trust hospitals. ${ }^{14}$ The visits were either a potential confounder of the study factor if the authors were only interested in the effect of screening, or visits acted as a potential interaction term, increasing the effect of screening. There were other patient-safety activities (potential confounders) during the screening campaign, including the Cleanyourhands campaign in 2004 and the Saving Lives campaign in $2005^{14}$ and an announcement by the Department of Health in late 2005 that all Acute Trust hospitals were to halve the rate of MRSA bacteremia. ${ }^{71}$ During the Cleanyourhands campaign, the purchase of soap and ABHR trended up in the first 4 years, and by 2008 the product usage had tripled compared with procurement at baseline. ${ }^{14}$ The amount of ABHR procured was associated 
with a significant decline in MRSA bacteremia and CDI, but only after 4 years when other multiple campaigns were also implemented. Therefore, ABHR procurement is a study factor when examined alone or as a potential confounder of screening if the aim was to establish the effect of screening on infection reduction alone. However, the contribution of each on reducing infection can be established during analysis if data for each potential confounder are measured.

After the early years of the Cleanyourhands campaign, the rate of MRSA bacteremia rate for 2005-2006 was 1.88 per 10,000 bed-days and fell to 0.91 per 10,000 bed-days by 2008. ${ }^{14}$ The rate of CDI infection fell from 16.75 in 2004 to 9.49 per 10,000 bed-days by 2008. By 2011-2012, MRSA rates were further reduced by $18 \%$ to 0.32 per 10,000 bed-days. ${ }^{69}$ A national 1 -week prevalence survey in May 2011 found that 86\% (144/167) of Trust hospitals were complying with screening (study factor): $61 \%$ of all emergency surgical admissions, and $81 \%$ of elective surgery admissions. ${ }^{72}$ The directive of preemptively isolating patients before the results (study factor) were known was complied by just $16 \%$ of patients screened on admission, but just over half, 55\%, of MRSA-positive patients were isolated after results were known. By 2011, colonization on admission was lower, $1.5 \%$, than previously identified at $2.4 \%$ in emergency admissions, ${ }^{73}$ and MRSA bacteremia declined between April 2009 and June 2011 by $38 \%{ }^{74}$ Between 2010 and 2014, the pattern in declining numbers of positive screened admissions continued and was attributed to a general decline of MRSA in England. ${ }^{74}$ The impact of universal screening on MRSA bacteremia rate was impressive, with rates declining even further from 1.24 per 100,000 bed-days in 2013 to 1.14 per 100,000 bed-days in 2014 . The halving of the CDI rate could have been assisted by the isolation of patients when they screened positive for MRSA. Screening and isolation did not affect MSSA bacteremia, which remained stable, between 7.73 and 7.9 per 100,000 bed-days. ${ }^{74}$ Universal screening and Cleanyourhands were concurrent study factors, and the authors acknowledged that to disentangle the multiple components of the screening program from hand hygiene was difficult. ${ }^{14,69}$ Results from the multiple strategies was considered to result in a "heroic national effort" but the authors overtly acknowledged that a $50 \%$ plus reduction in MRSA over a 2-year period was likely to be the "contribution of other intervention(s)" ${ }^{70}$ That is, they acknowledged that the effect of the screening program was confounded by other study factors, one of which was Cleanyourhands. The authors reported that the procurement of ABHR and a reduction in MRSA in the UK became significant only in the fourth quarter of each year of the study. ${ }^{14}$ For every $10 \mathrm{~mL}$ of ABHR procured per bed-day, a reduction of MRSA of 4.9\%-14.3\% was achieved, while MSSA bacteremia was not influenced by ABHR procurement. ${ }^{14}$

The National Veterans' Affair hospitals implemented an MRSA bundle in 2007 that consisted of universal screening, contact precautions, hand hygiene, and an institutional culture for infection control. ${ }^{75}$ By 2010 , screening had reached $96 \%$, and MRSA infection in ICU declined significantly by $62 \%$ and in non-ICU wards by $42 \% .{ }^{75}$ Other hospitals introduced MRSA screening and contact precaution in the USA in 2009 using the B-A design, ${ }^{76,77}$ which were successful in reducing MRSA infection in medical and surgical ICUs. ${ }^{76} \mathrm{~A}$ hospitalwide MRSA screening for all patients was compared with screening only high-risk patients along with single room and gloves and gown for HCWs. ${ }^{78}$ Screening all patients was no more successful in reducing MRSA than screening only high-risk patients. ${ }^{78}$ The rates for hand hygiene may have been different in the two periods of this B-A study and confounded the results; however, compliance rates were not provided. The Netherlands has aggressively implemented an MRSA control program for over a decade, which has been accredited with preventing 520,000 fewer infections per year. ${ }^{79}$ However, disentangling the screening effect from other elements of an MRSA bundle or concurrent bundles aimed at reducing other HAIs was not undertaken, and the level of hand hygiene compliance was not provided. In France, no association could be found between hand hygiene, ABHR consumption, and MRSA infection. ${ }^{80}$ In Scotland, the effect of MRSA screening, ${ }^{81}$ hand hygiene alone, or hand hygiene in combination with screening was examined. ${ }^{66}$ The rate of MRSA per 1,000 acute occupied bed-days (AOBDs) was declining during 2006 prior to a peak in the incidence of MRSA, ${ }^{66}$ which coincided with the introduction of a national hand hygiene ${ }^{82}$ program (study factor) in January 2007. Thereafter, the pattern of MRSA bacteremia remained chaotic until the introduction of a second study factor, the universal screening in July 2008. In response to an increase in the use of fluoroquinolones and cephalosporins, another study factor, namely the antibiotic stewardship program, was introduced in April 2009. In the period after the introduction of antibiotic stewardship, the rate of bacteremia remained low with an occasional spike in the incidence, but the stewardship program, the last study factor to be introduced, was credited with the reduction in MRSA by $0.027 / 1,000$ AOBDs. The percentage of SAB infections involving MRSA fell by $52 \%$. The Scottish national hand hygiene program, "Germs - wash your hands of them", was launched in $2007 .{ }^{82}$ However, 
hand hygiene compliance did not have a significant effect on MRSA or MSSA bacteremia. The rate of $S$. aureus bacteremia infection between 2006 and 2010 declined by $41 \%$ and was attributed to a reduction in MRSA bacteremia after the introduction of universal screening. ${ }^{66} \mathrm{~A}$ staggered introduction of study factors does not always provide clear results if study factors take time to impact or interact with other study factors.

The frequency of MRSA is approximately one-third of all S. aureus infections in inpatients, ${ }^{83}$ and the ability to detect a statistically significant change in MRSA rates in a single facility can be difficult. In Australia, S. aureus infections, in particular MRSA, have been declining in the years preceding hand hygiene interventions. ${ }^{84}$ For several years, MRSA was used as an indicator of patient safety and categorized as "MRSA sterile site" and "MRSA non-sterile site" infection stratified by ICU and non-ICU wards. The authors noted that the rate of "MRSA non-sterile sites" infection was trending down in Australia ${ }^{84}$ before the New South Wales (NSW) statewide hand hygiene campaign commenced in 2006 before all Australian public hospitals joined the national hand hygiene program by $2010 .{ }^{13} \mathrm{~A}$ decline in "MRSA non-sterile sites in ICU" and "MRSA non-ICU wards" occurred between 2005 and 2006 in Queensland, a state in Australia, which collected MRSA indicator data but had not yet introduced a statewide hand hygiene program. ${ }^{84}$ The authors noted that, in this 2-year period, the Queensland rate of "MRSA non-sterile sites in ICU" declined by 11 infections, 22.66/1,000 patient bed-days to $11.21 / 1,000$ patient bed-days $(P=0.003)$, and in "MRSA non-ICU wards" by 156 infections, $2.72-1.09 / 1,000$ patient bed-days $(P<0.001) .{ }^{84}$ During the same period, in Queensland no significant change was detected for "MRSA sterile sites in ICU", 10.96 to $6.73 / 1,000$ patient bed-days $(P=0.245) .{ }^{84}$ Prior to a statewide hand hygiene program across Victoria, MRSA declined in one hospital with a hand hygiene program. ${ }^{85}$ Prior to this program in Victoria, however, there was a downward trend in "MRSA from non-sterile sites in ICU" to achieve $2.66 / 1,000$ patient bed-days, after 21 infections were saved $(P<0.001)$ across the state. ${ }^{84}$ In NSW, the statewide hand hygiene program was initiated in 2006 after collecting preimplementation data in $2005 .{ }^{86}$ By 2008 , compliance had improved 14 percentage points, from $47 \%$ to $61 \% .{ }^{87}$ The rate of "MRSA non-sterile site in ICU" declined significantly by 14 infections, 41.7-24.22/1,000 patient bed-days $(P<0.001)$, and "MRSA non-sterile sites in non-ICU wards" by 121 infections, 5.71-3.06/1,000 patient bed-days, $P=0.001) .{ }^{84}$ From the SAB and MRSA infection rates in Australia reviewed elsewhere, ${ }^{88}$ a decline in rates commenced in 2002 prior to the 2006 NSW program and the Australian national hand hygiene program in 2010 . These data ${ }^{88}$ illustrate that, between 2002 and 2005, the MRSA rates in Australia were trending down by $39 \%$, from $0.77 / 10,000$ patient-days to $0.47 / 10,000$ patient-days. ${ }^{88}$ The SAB rates were also declining in Australia over this period by $20 \%$, from 1.72 to $1.38 / 10,000$ patientdays.$^{88}$ Between 2008 and 2009, the MRSA and SAB rates had declined by $12 \%$ and $18 \%$, respectively; ${ }^{88}$ this period represents the end of the NSW campaign and the commencement of the national campaign in all Australian hospitals. Factors associated with the downward trend in infection in Australia prior to the state-wide and national programs were not identified. ${ }^{84}$ State rates were becoming statistically rare, ${ }^{84,88}$ and any further significant downward trending will be difficult to detect and attribute to specific infection prevention strategies in an individual institute.

Prior to the Australian national campaign, NSW implemented a successful CLABSI aseptic insertion bundle in all ICUs between 2007 and 2008. ${ }^{22}$ After 12 months of implementation, the CLABSI in NSW had reached close to zero. ${ }^{89}$ The bundle required hand hygiene prior to gloving, Moment 2, and on removal of gloves, Moment 3/4. Integral to the bundle were selection of the preferred insertion site, skin preparation and fully draping the patient, CVC insertion training, and a check for the location of the CVC using a transducer or X-ray. Confounders included dwell time, which was associated with an increased probability of CLABSI, ${ }^{89}$ daily chlorhexidine and chlorhexidine-impregnated dressings, ${ }^{36,37,90,91}$ impregnated lines, ${ }^{92}$ and locks. ${ }^{93,94}$ The effect of the Australian National Hand Hygiene Initiative (study factor) on HAI rates (outcome factor) cannot easily be established, as another study factor that is a potential confounder of hand hygiene was the national roll out of the CLABSI bundle in late 2011.95

A multicentered study of ten hospitals employed an infection control strategy specifically for MRSA that used screening, contact precautions, and decolonization, and was compared with just an enhanced hand hygiene program. ${ }^{65}$ The ten hospitals represented Europe and Israel and surgical ward subspecialties: abdominal, cardiovascular, general, orthopedic, neurosurgical, urology, and vascular. Four hospitals were allocated into each intervention, and two hospitals received the combined strategies. A difference in total admissions from the highest to the lowest admission rate, between the ten hospitals, was of a magnitude of 6 and the number of beds in the wards differed by as much as 8 times. The nurse-to-patient ratio ranged from 3.7 to 16.8 . The effects of these potential confounders were adjusted for in the analysis. In clean surgery wards, MRSA reduction strategies were associated with decreasing the rates 
of MRSA clinical cultures per monthly (adjusted incidence rate ratio [aIRR] 0.85) and MRSA infections per 100 admissions (aIRR 0.83). ${ }^{65}$ The baseline hand hygiene rates in the wards that experienced the combined strategies was $39.3 \%$ in the 230-bed surgical ward (abdominal, general, and orthopedic) that had a nurse-to-patient ratio of $3.7 .^{65}$ The baseline hand hygiene compliance was $76.5 \%$ for the 84 -bed surgical ward (abdominal, orthopedic, and vascular) with a nurse-to-patient ratio of $6.1 .^{65}$ Post-intervention compliance increased by approximately 20 percentage points for both wards. After controlling for the effect of confounding, these wards had a significant downward trend (aIRR 0.88) in MRSA per 100 clinical cultures each month. ${ }^{65}$ But neither intervention significantly reduced MRSA infection per 100 admissions or MRSA surgical infections per 100 procedures. Total MRSA in both wards was low at baseline, and no intervention resulted in a significant decline. Both wards had different levels of compliance improvement. Neither the percentage point improvement in hand hygiene nor the final compliance rate may have been sufficiently high to impact on the transmission rates. In the larger hospitals, the improvement was large, 20 percentage points, but the final compliance rate was just $60 \%$. The baseline compliance in the smaller hospital was higher, $76 \%$, but improvement was negligible, 4 percentage points. These compliance rates may have been too low to induce improvement in an already statistically low MRSA infection rate. The Lee et $\mathrm{al}^{65}$ study has wide generalizability, as hospitals were enrolled from low to high resourced settings, and the exposure to enhanced hand hygiene and screening produced a steady rate of screening per month, $12 \%$, and a steady rate of MRSA isolates over the entire study period. Even after adjusting the analysis for patient to staff ratio, the difference in patient risk factors and baseline hand hygiene rates may have prevented the study factors from succeeding. ${ }^{65}$ The failure to produce a reduction in MRSA may not have been a failure of the interventions but due to statistically low rates of MRSA preventing an observed effect. Hand hygiene campaigns are unlikely to produce immediate impact because behavioral change requires a longer period to become embedded as normative behavior - years not months may be required to sustain any change. ${ }^{57}$ When the Lee et al ${ }^{65}$ study ceased, there was an increase in MRSA rates, suggesting that some impact had occurred but just not statistically measurable immediately after intervention. A selection of patients can help the success of infection prevention strategies (study factors) when particular risk factors benefit from the intervention better than other risk factors. This reduces generalizability of the study factor to a specific population. This was demonstrated in the effect of a solo intervention of decolonizing patients with MRSA using mupirocin. ${ }^{96}$ Decolonization of patients having clean surgery, such as orthopedic and cardiovascular procedures, was more likely to have an immediate impact on the MRSA infection rate compared with decolonization of patients having general surgery. ${ }^{96}$

Follow-up of positive screening results to decolonize or isolate the patient will bias the report of a hand hygiene program toward the successful reduction of MRSA infection. ${ }^{97}$ But hand hygiene campaigns may appear to have failed due to false-negative MRSA results from routine clinical cultures in patients who continue to be a silent reservoir of infection. ${ }^{97}$ If a positive screening result from previously false-negative patients occurs during a poorly performing hand hygiene audit, a link between poor compliance and MRSA may be incorrectly made. Hand hygiene campaigns may also appear to underperform because the human audit method does not reflect accurate ABHR usage. A review of studies from 12 countries, where confounding for country and other factors were not controlled, identified that ABHR usage correlated with MRSA infection, but hand hygiene compliance did not. ${ }^{98}$

\section{In conclusion: it's complicated}

In highly resourced health care settings, patients are at increased risk of HAIs when they are exposed to peripheral catheters, CVCs for medication, and parenteral nutrition, surgery, and indwelling urinary catheters. It is common to link hand hygiene interventions to infection reduction without reporting other prevention strategies associated with these high-risk exposures. The logic that good hand hygiene compliance contributes to the prevention of HAIs is accepted. Yet, hand hygiene alone cannot singularly inhibit the influence of formidable risk factors such as HAI acquisition at an older age, ${ }^{99}$ admission to the ICU, ${ }^{74}$ length of stay longer than average, ${ }^{100}$ or the fourfold increased risk of infection in patients colonized with $S$. aureus. ${ }^{81,101-103}$ Attempts to prevent HAIs, specifically bacteremia, require multiple concurrent interventions, ${ }^{34,104-106}$ and authors too eager to attribute a reduction in HAIs solely to a hand hygiene intervention do not advance evidence-based practice. Readers may be misled unless they are trained to recognize an inadvertent "spin" about the strength of the relationship between hand hygiene intervention and HAI reduction. The ORION 22-item checklist is an excellent attempt at assisting authors to systematically provide a critical appraisal of their RCT and non-RCT interventions to reduce HAIs. ${ }^{107}$ The checklist requires authors to describe plausible threats to the validity of the results, and this can be achieved by following the list even when the epidemiologic principles are not fully appreciated. If the checklist is read prior to designing an intervention, 
forewarning the authors about important errors, then attempts can be made to minimize each through study designs such as increasing the follow-up period for measuring compliance, estimating or acknowledging the Hawthorne effect, measuring exposure to the intervention components, and adjusting for confounders during the analysis. In addition, readers can be assisted with a short, mandatory open disclosure statement made by the authors in the discussion section that overtly outlines all infection improvement activities concurrent with the hand hygiene intervention.

When authors attempt to link the contribution of hand hygiene to a statistically rare event such as HAI, epidemiologists think about the complications produced by the various measurement errors, biases, and confounders and will tell you that, like all statistical relationships, this one is complicated.

\section{Disclosure}

Between 2005-2013 ML McLaws was advisor to the World Health Organization (WHO) Clean Care is Safer Care Guidelines and WHO First Global Patient Safety Challenge Clean Care Saves Lives. Between 2005-2009 she was advisor to the Clinical Excellence Commission Clean Hands Save Lives Campaign, NSW, Australia. The author reports no other conflicts of interest in this work.

\section{References}

1. Labarraque AG. Instructions and Observations Regarding the Use of the Chlorides of Soda and Lime. Porter J, trans-ed [French]. New Haven, CT: Baldwin and Treadway; 1829.

2. Semmelweis I. Etiology, Concept, and Prophylaxis of Childbed Fever. 1st ed. Carter KC, trans-ed. Madison, WI: The University of Wisconsin Press; 1983.

3. Rountree PM, Freeman BM, Barbour RG. Nasal carriage of Staphylococcus aureus in the general population and its relationship to hospitalization and to penicillin therapy. Med J Aust. 1954;2(12):457-460.

4. Lowy EJL, Lilly HA, Bull JP. Disinfection of hands: removal of transient organism. Br Med J. 1964;2(5403):230-233.

5. Sanford MD, Widmer AF, Bale MJ, Jones RN, Wenzel RP. Efficient detection and long-term persistence of the carriage of Methicillin-resistant Staphylococcus aureus. Clin Infect Dis. 1994;19:1123-1128.

6. Larson EL, Cronquist AB, Whittier S, Lai L, Lyle CT, Della Latta P. Differences in skin flora between inpatients and chronically ill patients. Heart Lung. 2000;29:298-305.

7. Steere AC, Mallison GF. Handwashing practices for the prevention of nosocomial infections. Ann Intern Med. 1975;83:683-690.

8. Garner JS, Favero MS. CDC guideline for handwashing and hospital environmental control, 1985. Infect Control. 1986;7:231-243.

9. Larson EL; APIC Guidelines Committee. APIC guideline for handwashing and hand antisepsis in health care settings. Am J Infect Control. 1995;23:251-269.

10. Boyce JM, Pittet D; Centers for Disease Control. Guideline for hand hygiene in health-care settings. Recommendations of the healthcare infection control practices advisory committee and the HICPAC/ SHEA/APIC/IDSA hand hygiene task force. Society for Healthcare epidemiology of America/Association for professionals in infection control/infectious diseases Society of America. MMWR Recomm Rep. 2002;51(RR-16):1-48.
11. WHO. WHO Guidelines on Hand Hygiene in Health Care: First Global Patient Safety Challenge Clean Care is Safer Care. Geneva: World Health Organization; 2009.

12. Sax H, Allegranzi B, Uckay I, Larson E, Boyce J, Pittet D. My five moments for hand hygiene': a user-centred design approach to understand, train, monitor and report hand hygiene. J Hosp Infect. 2007;67:9-21.

13. Grayson ML, Russo PL, Cruickshank M, et al. Outcomes from the first 2 years of the Australian national hand hygiene initiative. Med J Aust. 2011;195(10):615-619.

14. Stone SP, Fuller C, Savage J, et al. Evaluation of the national Clean your hands campaign to reduce Staphylococcus aureus bacteraemia and Clostridium difficile infection in hospitals in England and Wales by improved hand hygiene: four year, prospective, ecological, interrupted time series study. BMJ. 2012;344:e3005.

15. Allegranzi B, Gayet-Ageron A, Bengaly L, et al. Global implementation of the WHO multimodal hand hygiene promotion strategy across facilities worldwide. Lancet. 2013;13(10):843-851.

16. Pronovost P, Needham D, Berenholtz S, et al. An intervention to decrease catheter-related bloodstream infections in the ICU. $N$ Engl J Med. 2006;355(26):2725-2732.

17. Pratt RJ, Pellowe CM, Wilson JA, et al. Epic 2: national evidence-based guidelines for preventing healthcare-associated infections in NHS hospitals in England. J Hosp Infect. 2007;65:S2-S127.

18. Gould CV, Umscheid CA, Agarwal RK, Kuntz G, Pegues DA; The Healthcare Infection Control Practices Advisory Committee (HICPAC). Guideline for Prevention of Catheter-Associated Urinary Tract Infections 2009. Healthcare Infection control practices Advisory Committee (HICPAC), CDC; 2009. Available from: http://www.cdc. gov/hicpac/pdf/cauti/cautiguideline2009final.pdf. Accessed December 24, 2014.

19. Curley MA, Schwalenstocker E, Deshpande JK, et al. Tailoring the institute for health care improvement 100,000 lives campaign to pediatric settings: the example of ventilator-associated pneumonia. Pediatr Clin North Am. 2006;53(6):1231-1251.

20. Resar R, Griffin FA, Haraden C, Nolan TW. Using Care Bundles to Improve Health Care Quality. IHI Innovation Series White Paper. Cambridge, MA: Institute for Healthcare Improvement; 2012. Available from: http://www.IHI.org.

21. Rello J, Lode H, Cornaglia G, Masterton R. VAP care bundle contributors. A European care bundle for prevention of ventilatorassociated pneumonia. Intensive Care Med. 2010;36:773-780.

22. Burrell A, McLaws ML, Herkes R, Mungo M, Pantle A. Aseptic insertion of central lines reduces bacteraemia. Med J Aust. 2011;194(11): $583-587$.

23. Rosenthal VD, Maki DG, Rodrigues C, et al. Impact of international nosocomial infection control consortium (INICC) strategy on central line-associated bloodstream infection rates in the intensive care units of 15 developing countries. Infect Control Hosp Epidemiol. 2010;31: 1264-1272.

24. Amine AE, Helal MO, Bakr WM. Evaluation of an intervention program to prevent hospital-acquired catheter-associated urinary tract infections in an ICU in a rural Egypt hospital. GMS Hyg Infect Control. 2014;9: Doc 15.

25. Coffin SE, Klompas M, Classen D, et al. Strategies to prevent ventilatorassociated pneumonia in acute care hospitals. Infect Control Hosp Epidemiol. 2008;29:S31-S40.

26. Lo E, Nicolle LE, Coffin SE, et al. Strategies to prevent catheterassociated urinary tract infections in acute care hospitals: 2014 update. Infect Control Hosp Epidemiol. 2014;35:464-479.

27. O'Grady NP, Alexander M, Burns LA, et al. Guidelines for the prevention of intravascular catheter-related infections. Am J Infect Control. 2011;39(4 suppl 1):S1-S34.

28. Bird D, Zambuto A, O'Donnell C, et al. Adherence to ventilator-associated pneumonia bundle and incidence of ventilator-associated pneumonia in the surgical intensive care unit. Arch Surg. 2010;145: $465-470$. 
29. Rosenthal VD, Alvarez-Moreno C, Villamil-Gomez W, et al. Effectiveness of a multidimensional approach to reduce ventilatorassociated pneumonia in pediatric intensive care units of 5 developing countries: international nosocomial infection control consortium findings. Am J Infect Control. 2012;40:497-501.

30. Rosenthal VD, Ramachandran B, Dueñas L, et al. Findings of the international nosocomial infection control consortium (INICC), part I: effectiveness of a multidimensional infection control approach on catheter-associated urinary tract infection rates in pediatric intensive care units of 6 developing countries. Infect Control Hosp Epidemiol. 2012;33:696-703.

31. Sax SF, Sax H, Wachsmuth M, Hoffmeyer P, Clergue F, Pittet D. Reduction of urinary tract infection and antibiotic use after surgery: a controlled, prospective, before-after intervention study. Clin Infect Dis. 2006;42:1544-1551.

32. Davis KF, Colebaugh AM, Eithun BL, et al. Reducing catheterassociated urinary tract infections: a quality-improvement initiative. Pediatrics. 2014;134:e857-e864.

33. Fakih MG, Krein SL, Edson B, Watson SR, Battles JB, Saint S. Engaging health care workers to prevent catheter-associated urinary tract infection and avert patient harm. Am J Infect Control. 2014;42(Suppl 10):S223-S229.

34. Bion J, Richardson A, Hibbert P, et al. Matching Michigan: a 2-year stepped interventional programme to minimise central venous catheterblood stream infections in intensive care units in England. BMJ Qual Saf. 2013;22:110-123.

35. Montecalvo MA, McKenna D, Yarrish R, et al. Chlorhexidine bathing to reduce central venous catheter-associated bloodstream infection: impact and sustainability. Am J Med. 2012;125:505-511.

36. Lorente L, Lecuona M, Jiménez A, et al. Cost/benefit analysis of chlorhexidine-silver sulfadiazine-impregnated venous catheters for femoral access. Am J Infect Control. 2014;42:1130-1132.

37. Kaki R, Elligsen M, Walker S, Simor A, Palmay L, Daneman N. Impact of antimicrobial stewardship in critical care: a systematic review. J Antimicrob Chemother. 2011;66:1223-1230.

38. Goodman ER, Platt R, Bass R, Onderdonk AB, Yokoe DS, Huang SS. Impact of an environmental cleaning intervention on the presence of methicillin-resistant Staphylococcus aureus and vancomycin-resistant enterococci on surfaces in intensive care unit rooms. Infect Control Hosp Epidemiol. 2008;29(7):593-599.

39. Dancer SJ. Controlling hospital-acquired infection: focus on the role of the environment and new technologies for decontamination. Clin Microbiol Rev. 2014;27:665-690.

40. Siegel JD, Rhinehart E, Jackson M, Chiarello L; Healthcare Infection Control Practices Advisory Committee. Guideline for Isolation Precautions: Preventing Transmission of Infectious Agents in Healthcare Settings; 2007. Available from: http://www.cdc.gov/ncidod/dhqp/pdf/ isolation2007.pdf. Accessed December 24, 2014.

41. The National Archives. Screening for Methicillin-Resistant Staphylococcus aureus (MRSA) Colonisation: A Strategy for NHSTrusts: A Summary of Best Practice; 2006. Available from: http://webarchive. nationalarchives.gov.uk/20130107105354/http://www.dh.gov.uk/en/ Publicationsandstatistics/Publications/PublicationsPolicyAndGuidance/ DH_063188. Accessed December 24, 2014.

42. Reilly JS, Stewart S, Christie P, et al. Universal screening for Meticillinresistant Staphylococcus aureus in acute care: risk factors and outcome from a multicentre study. $J$ Hosp Infect. 2012;80:31-35.

43. Cardo D, Dennehy PH, Halverson P, et al. Moving toward elimination of healthcare-associated infections: a call to action. Infect Control Hosp Epidemiol. 2010;31:1101-1105.

44. Martinez-Capolino C, Reyes K, Johnson L, et al. Impact of active surveillance on Methicillin-resistant Staphylococcus aureus transmission and hospital resource utilization. J Hosp Infect. 2010;74: 232-237.

45. Mathai E, Allegranzi B, Kilpatrick C, Nejad SB, Graafmans W, Pittet D. Promoting hand hygiene in healthcare through national/subnational campaigns. J Hosp Infect. 2011;77:294-298.
46. Al-Tawfiq JA, Abed MS, Al-Yami N, Birrer RB. Promoting and sustaining a hospital- wide, multifaceted hand hygiene program resulted in significant reduction in health care-associated infections. Am J Infect Control. 2013;41:482-486.

47. Erasmus V, Daha TJ, Brug H, et al. Systematic review of studies on compliance with hand hygiene guidelines in hospital care. Infect Control Hosp Epidemiol. 2010;31:283-294.

48. Allegranzi B, Sax H, Pittet D. Hand hygiene and healthcare system change within multi-modal promotion: a narrative review. J Hosp Infect. 2013;83:S3-S10.

49. Graves N. How costs change with infection prevention efforts. Curr Opin Infect Dis. 2014;27:390-393.

50. McKibben L, Horan T, Tokars JI, et al. Guidance on public reporting of healthcare-associated infections: recommendations of the healthcare infection control practices advisory committee. Am J Infect Control. 2005;33:217-226

51. Worth LJ, Bull AL, Richards MJ. Public reporting of health careassociated infection data in Australia: time to refine. Med J Aust. 2013;198:252-253.

52. Katz DL, Elmore JG, Wild DMG, Lucan SC. Jekel's Epidemiology, Biostatistics, Preventive Medicine, and Public Health. 4th ed. Philadelphia, PA: Elsevier Saunders; 2014.

53. Morgan DJ, Pineles L, Shardell M, et al. Automated hand hygiene count devices may better measure compliance than human observation. $\mathrm{Am}$ J Infect Control. 2012;40:955-959.

54. Diller T, Kelly JW, Blackhurst D, Steed C, Boeker S, McElveen DC. Estimation of hand hygiene opportunities on an adult medical ward using 24-hour camera surveillance: validation of the HOW2 benchmark study. Am J Infect Control. 2014;42:602-607.

55. Jayaraman SP, Klompas M, Bascom M, et al. Hand-Hygiene compliance does not predict rates of resistant infections in critically ill surgical patients. Surg Infect. 2014;15:533-539.

56. Prochaska JO, DiClemente CC, Norcross JC. In search of how people change. Am Psychol. 1992;27:1102-1114.

57. Helder OK, Brug J, van Goudoever JB, Looman CWN, Reiss IKM, Kornelisse RF. Sequential hand hygiene promotion contributes to a reduced nosocomial bloodstream infection rate among very low-birth weight infants: an interrupted time series over a 10 -year period. $\mathrm{Am} \mathrm{J}$ Infect Control. 2014;42:718-722.

58. Galluzzi V, Herman T, Shumaker DJ, et al. Electronic recognition of hand hygiene technique and duration. Infect Control Hosp Epidemiol. 2014;35:1298-1300.

59. Creamer E, Dorrian S, Dolan A, et al. When are the hands of healthcare workers positive for Methicillin-resistant Staphylococcus aureus? $J$ Hosp Infect. 2010;75:107-111.

60. Goroncy-Bermes P, Koburger T, Meyer B. Impact of the amount of hand rub applied in hygienic hand disinfection on the reduction of microbial counts on hands. J Hosp Infect. 2010;74:212-218.

61. Larson E, Strom MS, Evans CA. Analysis of three variables in sampling solutions used to assay bacteria of hands: type of solution, used of antiseptic neutralizers, and solution temperature. J Clin Microbiol. 1980;12:355-360.

62. McLaws ML. Epidemiology of Healthcare associated infections: uses, pitfalls and the future. In: Gilbert L, Iredell J, Merlino J, editors. Hospital Acquired Infections, Susceptibility Testing and Infection Control. Microbiology Australia; 2014. Available from: http://microbiology.publish. csiro.au/paper/MA14006.htm. Accessed December 24, 2014.

63. Mestre G, Berbel C, Tortajada P, et al. "The $3 / 3$ strategy": a successful multifaceted hospital wide hand hygiene intervention based on WHO and continuous quality improvement methodology. PLoS One. 2012;7:e47200.

64. Mears A, White A, Cookson B, et al. Healthcare-associated infection in acute hospitals: which interventions are effective? J Hosp Infect. 2009;71:307-313.

65. Lee AS, Cooper BS, Malhotra-Kumar S, et al. Comparison of strategies to reduce Meticillin-resistant Staphylococcus aureus rates in surgical patients: a controlled multicentre intervention trial. BMJ Open. 2013;3:e003126. 
66. Lawes T, Edwards B, Lopez-Lozano JM, Gould I. Trends in Staphylococcus aureus bacteraemia and impacts of infection control practices including universal MRSA admission screening in a hospital in Scotland, 2006-2010: retrospective cohort study and time-series intervention analysis. BMJ Open. 2012;2:e000797.

67. Mertens K, Morales I, Catry B. Infections acquired in intensive care units: results of national surveillance in Belgium, 1997-2010. J Hosp Infect. 2013;84:120-125.

68. Department of Health. Saving Lives: A Delivery Programme to Reduce Healthcare Associated Infection, Including MRSA Screening for Methicillin-Resistant Staphylococcus aureus (MRSA) Colonisation: A Strategy for NHS Trusts: A Summary of Best Practice; 2006. Available from: http://webarchive.nationalarchives.gov.uk/20130107105354/http:// www.dh.gov.uk/prod_consum_dh/groups/dh_digitalassets/@dh/@en/ documents/digitalasset/dh_063187.pdf. Accessed December 24, 2014.

69. Johnson AP, Davies J, Guy R, et al. Mandatory surveillance of Methicillin-resistant Staphylococcus aureus (MRSA) bacteraemia in England: the first 10 years. J Antimicrob Chemother. 2012;67: 802-809.

70. Edgeworth JD. Has decolonization played a central role in the decline in UK Methicillin-resistant Staphylococcus aureus transmission? A focus on evidence from intensive care. J Antimicrob Chemother. 2011;66(Suppl 2):41-47.

71. Patient Safety Alert. Alert 2 September 2004. NPSA clean your hands campaign economic evaluation, Department of Health; 2004. http://www.google.com.au/url?sa=t\&rct=j\&q=\&esrc=s\&source=we $\mathrm{b} \& \mathrm{~cd}=1 \&$ ved $=0 \mathrm{CB} 0 \mathrm{QFjAA} \& u r l=\mathrm{http} \% 3 \mathrm{~A} \% 2 \mathrm{~F} \% 2 \mathrm{Fwww} . n$ psa.nhs. uk\%2FEasySiteWeb\%2FGatewayLink.aspx\%3FalId\%3D75060\&ei= myaaVOPGJ4rm8gWwjYKQBg\&usg=AFQjCNHZExHqjWgUzilye JFp_ACCVyO6Pg\&sig2=W0d6cFpDlqfJ9jyq7hkNaw\&bvm=bv.820 01339,d.dGc. Accessed December 24, 2014.

72. Fuller C, Robotham J, Savage J, et al. The national one week prevalence audit of Universal Methicillin-resistant Staphylococcus aureus (MRSA) admission screening 2012. PLoS One. 2013;8:e74219.

73. Rao GP, Michalczyk P, Nayeem N, Walker G, Wigmore L, Wigmore L. Prevalence and risk factors for Meticillin-resistant Staphylococcus aureus in adult emergency admissions - a case for screening all patients? J Hosp Infect. 2007;66:15-21.

74. Public Health England. 2014. Available from: https://www.gov.uk/ government/uploads/system/uploads/attachment_data/file/356187/ QEC_September_2014.pdf. Accessed December 24, 2014.

75. Jain R, Kralovic SM, Evans ME, et al. Veterans Affairs initiative to prevent Methicillin-resistant Staphylococcus aureus infections. N Engl J Med. 2011;364:1419-1430.

76. Kjonegaard R, Fields W, Peddecord KM. Universal rapid screening for Methicillin-resistant Staphylococcus aureus in the intensive care units in a large community hospital. Am J Infect Control. 2013;41:45-50.

77. Walsh EE, Greene L, Kirshner R. Sustained reduction in Methicillin-resistant Staphylococcus aureus wound infections after cardiothoracic surgery. Arch Intern Med. 2011;171:68-73.

78. Leonhardt KK, Yakusheva O, Phelan D, et al. Clinical effectiveness and cost benefit of universal versus targeted Methicillin-resistant Staphylococcus aureus screening upon admission in hospitals. Infect Control Hosp Epidemiol. 2011;32:797-803.

79. Vriens M, Blok H, Fluit A, Troelstra A, van der Werken C, Verhoef J. Costs associated with a strict policy to eradicate Methicillin-resistant Staphylococcus aureus in a Dutch university medical centre: a ten year survey. Eur J Clin Microbiol Infect Dis. 2002;21:782-786.

80. Grammatico-Guillon L, Thiolet JM, Bernillon P, Coignard B, Khoshnood B, Desenclos JC. Relationship between the prevalence of Methicillin-resistant Staphylococcus aureus infection and indicators of nosocomial infection control measures: a population-based study in French hospitals. Infect Control Hosp Epidemiol. 2009;30: 861-869.

81. Reilly JS, Stewart S, Christie P, et al. Universal screening for Methicillin resistant Staphylococcus aureus: interim results from the NHS Scotland pathfinder project. J Hosp Infect. 2010;74:35e41.
82. Health Protection Scotland. National Hand Hygiene NHS Campaign. Compliance with Hand Hygiene - Audit Report. Glasgow, Scotland: Health Protection Scotland; 2010. Available from: http:// www.documents.hps.scot.nhs.uk/hai/infection-control/national-handhygiene-campaign/audit-report-2009-05-06.pdf. Accessed December 24, 2014.

83. Nimmo GR, Pearson JC, Collignon PJ; Australian Group on Antimicrobial Resistance. Antimicrobial susceptibility of Staphylococcus aureus isolated from hospital inpatients, 2009: report from the Australian group on antimicrobial resistance. Commun Dis Intell Q Rep. 2011;35: 237-243.

84. McLaws ML, Pantle AC, Fitzpatrick KR, Hughes CF. More than hand hygiene is needed to affect Methicillin-resistant Staphylococcus aureus clinical indicator rates: clean hands save lives, part IV. Med J Aust. 2009;191:S26-S31.

85. Harrington G, Watson K, Bailey M, et al. Reduction in hospital wide incidence of infection or colonisation with Methicillin-resistant Staphylococcus aureus with use of antimicrobial hand-hygiene gel and statistical process control charts. Infect Control Hosp Epidemiol. 2007;28:837-844.

86. Pantle AC, Fitzpatrick KR, McLaws ML, Hughes CF. A statewide approach to systematising hand hygiene behaviour in hospitals: clean hands save lives, part I. Med J Aust. 2009;191(Suppl 8): S8-S12.

87. McLaws ML, Pantle AC, Fitzpatrick KR, Hughes CF. Improvements in hand hygiene across New South Wales public hospitals: clean hands save lives, part III. Med J Aust. 2009;191(Supp1 8): S18-S25.

88. Mitchell BG, Collignon PJ, McCann R, Wilkinson IJ, Wells A. Major reduction in hospital-onset Staphylococcus aureus bacteremia in Australia - 12 years of progress: an observational study. Clin Infect Dis. 2014;59:969-975.

89. McLaws ML, Burrell A. Zero-risk for central line associated bloodstream infection: are we there yet? Crit Care Med. 2012;40: 388-393.

90. Dixon JM, Carver RL. Daily chlorohexidine gluconate bathing with impregnated cloths results in statistically significant reduction in central line-associated bloodstream infections. Am J Infect Control. 2010;38:817-821.

91. Derde LP, Dautzenberg MJ, Bonten MJ. Chlorhexidine body washing to control antimicrobial-resistant bacteria in intensive care units: a systematic review. Intensive Care Med. 2012;38:931-939.

92. Gilbert RE, Harden M. Effectiveness of impregnated central venous catheters for catheter related blood stream infection: a systematic review. Curr Opin Infect Dis. 2008;21:235-245.

93. Oliveira C, Nasr A, Brindle M, Wales PW. Ethanol locks to prevent catheter- related bloodstream infections in parenteral nutrition: a meta-analysis. Pediatrics. 2012;129:318-329.

94. Jones BA, Hull MA, Richardson DS, et al. Efficacy of ethanol locks in reducing central venous catheter infections in pediatric patients with intestinal failure. J Pediatr Surg. 2010;45:1287-1293.

95. ANZICS. 2014. Available from: http://www.anzics.com.au/safetyquality/clab. Accessed December 24, 2014.

96. Kallen AJ, Wilson CT, Larson RJ. Perioperative intranasal mupirocin for the prevention of surgical-site infections: systematic review of the literature and meta-analysis. Infect Control Hosp Epidemiol. 2005;26 916-922.

97. Noorani HZ, Adams E, Glick S, Weber S, Belinson S, Aronson N Screening for Methicillin-Resistant Staphylococcus aureus (MRSA) Future Research Needs. Future Research Needs Paper No 40. (Prepared by the Blue Cross and Blue Shield Association Technology Evaluation Center Evidence-based Practice Center under Contract No 290-2007-10058-I.) AHRQ Publication No 13-EHC056-EF. Rockville, MD: Agency for Healthcare Research and Quality; 2013. Available from: http://www.effectivehealthcare.ahrq.gov/ reports.final.cfm. Accessed December 24, 2014

98. Sroka S, Gastermeier P, Meyer E. Impact of alcohol based hand-rub on Methicillin resistant Staphylococcus aureus: an analysis of the literature. J Hosp Infect. 2010;74:2014-2211. 
99. Wyllie DH, Crook DW, Peto TE. Mortality after Staphylococcus aureus bacteraemia in two hospitals in Oxfordshire, 1997-2003: cohort study. BMJ. 2006;333:281e6.

100. Thwaites GE. United Kingdom clinical infection research group (UKCIRG). The management of Staphylococcus aureus bacteraemia in the United Kingdom and Vietnam: a multi-centre evaluation. PLoS One. 2010;5:e14170.

101. Seybold U, Schubert S, Bogner JR, Hogardt M. Staphylococcus aureus infection following nasal colonisation: an approach to rapid risk stratification in a university healthcare system. J Hosp Infect. 2011;79:297e301.

102. Honda H, Krauss MJ, Coopersmith CM, et al. Staphylococcus aureus nasal colonization and subsequent infection in intensive care unit patients: does Methicillin resistance matter? Infect Control Hosp Epidemiol. 2010;31:584e91.

103. Safdar N, Bradley EA. The risk of infection after nasal colonization with Staphylococcus aureus. Am J Med. 2008;121:310-315.
104. Cooke J, Stephens P, Ashiru-Oredope D, Johnson AP, Livermore DM, Sharland M. Antimicrobial stewardship sub-group of the department of health's advisory committee for antimicrobial resistance and healthcare associated infection. Antibacterial usage in English NHS hospitals as part of a national antimicrobial stewardship programme. Public Health. 2014;128:693-697.

105. Dunn-Navarra AM, Cohen B, Stone PW, Pogorzelska M, Jordan S, Larson E. Relationship between systems-level factors and hand hygiene adherence. J Nurs Care Qual. 2011;26:30-38.

106. Borg MA, Hulscher M, Scicluna EA, et al. Prevention of Meticillin-resistant Staphylococcus aureus bloodstream infections in European hospitals: moving beyond policies. J Hosp Infect. 2014;87: 203-211.

107. Stone SP, Cooper BS, Kibber CC, et al. The ORION statement: guidelines for transparent reporting of outbreak reports and intervention studies of nosocomial infection. J Antimicrob Chemother. 2007;59: 833-840.

\section{Publish your work in this journal}

Infection and Drug Resistance is an international, peer-reviewed openaccess journal that focuses on the optimal treatment of infection (bacterial, fungal and viral) and the development and institution of preventive strategies to minimize the development and spread of resistance. The journal is specifically concerned with the epidemiology of antibiotic

\section{Dovepress}

resistance and the mechanisms of resistance development and diffusion in both hospitals and the community. The manuscript management system is completely online and includes a very quick and fair peerreview system, which is all easy to use. Visit http://www.dovepress.com/ testimonials.php to read real quotes from published authors. 